\title{
THE EFFICIENCY RESEARCH OF THE OAT AND PROSO MARKET IN THE MODERN KAZAKHSTAN
}

\author{
Marita Baltabayevna Kadyrbekova
}

Kazakh National Agrarian University, Almaty, Republic of Kazakhstan

\begin{abstract}
This article researches how efficient is the oat and proso market in the Republic of Kazakhstan. Moreover, this work offers recommendations to improve operational efficiency of the oat and proso market in Kazakhstan. The research purpose is to offer theoretical and practical background that describes how to use economic mechanisms to develop the agrarian economy in Kazakhstan. The research observation consists of comparative, quantitative, econometric and analytical methods. The research result is to research the efficiency of the internal oat and proso market in Kazakhstan. The research conclusion shows that the Kostanay province is among the leaders in growing oats and the Pavlodar province in growing proso.
\end{abstract}

Keywords: proso, oats, harvested area, gross collection, yielding capacity

In the Address of President Nursultan Nazarbayev to the people of Kazakhstan, the "Strategy Kazakhstan-2050 states that it is necessary to actively develop strategies for the formation of new market niches for domestic producers in the most competitive sectors of the national economy. This will help in avoiding potentially destructive effects of de-industrialization, especially taking into account the prospect of joining the WTO". Kazakhstan is consistently among the 10 largest exporters of oats and proso in the world. In the republic, the production of oats and proso is the strategic basis for the development of agriculture, the level of its production determines the degree of food security of the country. Ensuring food safety plays an important role in maintaining national security. Therefore, growing vegetables that have potential for the food industry can lead to economic growth. Oats and proso are referred to as agricultural crops, which can be used for further processing to create more complex food products and for domestic consumption by the local population. According to the forecasts of the Food and Agriculture Organization of the United Nations (FA0), the growth of global production of oats and proso until 2020 is expected at $11 \%$. Kazakhstan will increase the production of oats and proso by $40 \%$ mainly due to increased yields. The growth of global production of forage oats and proso will go at an accelerating rate in relation to food, by about 20\%. The production of oats and proso is the most prioritized sector in the development of agriculture in Kazakhstan. It occupies one of the leading places in the agro-industrial complex and in the whole economy of Kazakhstan. In Kazakhstan, about $80 \%$ of the total acreage is oats and proso crops. The main production base for oats and proso is located in the northern region. Favourable natural conditions in this region make it possible to obtain high and stable yields of oats and proso, first of all, food oats and proso with a high content of gluten, which is in great demand on world markets. The total share of the northern regions of Kazakhstan (Akmola, Kostanay, North Kazakhstan) in the total volume of production of oats and proso is about 75\%. According to average data, over the past five years, the annual carryover stocks of oats and proso are about 14 million tons. As of November 1, 2016, oats and proso crops in Kazakhstan amounted to 18.84 million tons. For the period from the beginning of the 1990s to 2012, oats and proso were the most important in terms of yield (13.2 metric hundredweights per hectare) and gross harvest (29.8 million tons) in 1992. The same harvest of oats and proso in the republic was collected in 2011 (26.9 million tons), with a yield of 16.9 metric hundredweight/ha. Over the past seven years, oat and proso production has fluctuated between 11.8 and 26.6 million tons in weight after completion. 2011 was a record year - the gross yield was 26.6 million tons, and the crop was poor in 2010. Two factors influenced the change in production: changes in crop areas and yields.

\section{Material and Methods}

The theoretical and methodological basis of the study was established by the works of domestic and foreign economists on problems of the development of the agrarian sphere of the economy, the agrifood market, the grain-based subcomplex, the grain farm and the grain market. The initial research base was the scientific works of Kazakhstan's scientific institutions of the country, the data of the Agency of the Republic of Kazakhstan on Statistics, statistical collections of the Federal State Statistics Service, regulatory documents of the republican and regional government bodies on the organization of state and local government; Republic of Kazakhstan laws and regulations, the governments of the Republic of Kazakhstan, as well as regulatory legal acts of federal, republican and provincial authorities on the development of the agrarian sphere of the economy, the agro-food market and its individual product segments. Also, statistical data of the Committee on Statistics of the Ministry of National Economy, the Customs Committee, analytical reviews of the grain market and annual reports were used as initial data. Statistics on the grain industry, as well as other industries are subject to seasonal fluctuations, it is customary to beat for a conditional, so-called marketing year. Other sources are the studies conducted on the basis of materials and annual reports of the Ministry of Agriculture of the Republic of Kazakhstan, the State Statistics Committee of the Republic of Kazakhstan, the Interstate Statistical Committee of the Commonwealth of Independent States, the State Customs Committee 
of the Republic of Kazakhstan, as well as legislative acts, resolutions and orders of the governments of the CIS member states, developments carried out by experts of a group of specialists within the framework of the project, generalization of foreign experience the subject in question.

In the course of the research, methods of statistical and comparative analysis and a systematic approach to studying the infrastructure of the grain market and grain exports were applied. In addition, methods of structural-functional analysis, analysis and synthesis, and expert evaluations were used. For the processing of materials, various methods of economic research were used:
$\square$ abstract-logical,
$\square$ economic and statistical,
$\square$ monographic,
$\square$ computationally constructive,
$\square$ graphic,
$\square$ expert,
$\square$ balance methods and others.

The scientific novelty of the research is as follows:

$\square$ development of the general theory of the market as a system of economic relations, justification of the mechanism of its functioning, regulation and trends of change;

$\square$ in the scientific substantiation of the conceptual provisions for ensuring food security of the country and regions on the basis of the formation of public resources of oats and proso;

$\square$ in the development of scientific bases for the development of the regional market of oats and proso in the conditions of North Kazakhstan; in justification of the system of organizational and economic measures and economic efficiency of sustainable development of oats and proso.

\section{Results and discussion}

Oats and proso cultures are grown everywhere except the Mangystau region, but the main producer of oats and proso crops is the northern region (Akmola, Kostanay, North Kazakhstan and Pavlodar regions), which accounted for more than $84 \%$ of the total gross harvest in the republic in 2011. In these areas, oats and proso crops are grown on rainfed lands and therefore their production is not sustainable and the harvest is strongly influenced by weather conditions. Out of five years, almost three years in the country are arid. The existing level of technical equipment of agricultural production is also the main deterrent to its effective development. To date, the park of the agricultural republic, according to experts, is worn out by $80 \%$. And if today does not take up its updating, then in four years the capacity of the park of agricultural machinery in the country will be only $23 \%$, which gives grounds to speak about the big losses of the grown crops. The annual losses of the Kazakh economy due to the shortage of modern agricultural machinery are from 45 to 90 million dollars, depending on the yield and climatic conditions during the harvesting period. The pace of renewal of the park of agricultural machines remains extremely low, and for the absolute majority of agricultural enterprises, and first of all, for medium and small farms that do not have access to credit resources, it is generally an impossible dream, and the means intended for the development of the leasing program are inadequate and mainly attributed to large oats and proso companies and large agricultural enterprises. The spread of pests and plant diseases and soil degradation (loss of humus from the soil) lead to a decrease in the quality and quantity of products. Annually, from the national budget about 2.5-3.0 billion tenge is allocated for plant protection, due to which the struggle with especially dangerous harmful organisms of agricultural crops is carried out on an area of 3.0-3.5 million hectares. About 740-900 million tenge are allocated annually to identify, localize and liquidate quarantine objects (The Committee on Statistics, Ministry of National Economy of the Republic of Kazakhstan, 2018).

This makes it possible to conduct chemical treatment against quarantine objects on an area of about 180-190 thousand hectares. The quality of sown seeds does not meet the requirements. At present, funds are allocated from the national budget for testing the quality of seeds. In the republic, areas under cultivated crops of oats and proso crops remain low and do not exceed $72 \%$. The level of application of mineral fertilizers under crops still remains low. In 2011, only 677.0 thousand hectares of agricultural land were fertilized. This is only $3.2 \%$ of the total sown area, or 0.6 metric hundredweights per hectare. In 2011, 41.5 thousand tons of mineral fertilizers were added, in terms of $100 \%$ of nutrients. Since 2003 , the state subsidizes up to $40 \%$ of the value of mineral fertilizers purchased by agricultural producers. But the use of fertilizers in agricultural production still remains at a high level, not to mention that it does not at all correspond to the scientific norms of consumption. One of the problems in the production of oats and proso crops is a reduction in the amount of seed dressing and chemical weeding. Until 1990, seed dressing of oats and proso crops was carried out, as a rule, in full extent. Since 1991, the amount of seed dressing has been decreasing from year to year. As a result, intensive accumulation of phytopathogens occurs in the soil and in the seed material, and as a result, the disease with head diseases has increased, and there is an increase in the infestation with oats. According to the survey data, in the republic for 14.8 million hectares of sown area a chemical control was carried out against wild oats. Work is underway to process quarantine objects. Field studies conducted in the Akmola, Kostanay and North Kazakhstan regions found that due to the improvement of crops from the glands and other diseases that stimulate the growth of the root system, many preparations increase the yield of oats and proso crops from $0.5-0.7$ up to $1-2$ ts/ha oats and proso. As a result, the costs incurred for dressing pay off $2-3$ times or more. Another problem of production of oats and proso is the non-harmonization of quality standards with international ones, which is not an unimportant factor when Kazakhstan joins the WTO (The Committee on Statistics, Ministry of National Economy of the Republic of Kazakhstan, 2018).

The figure below shows the volume of oats available on 1 December 2017 in Kazakhstan.

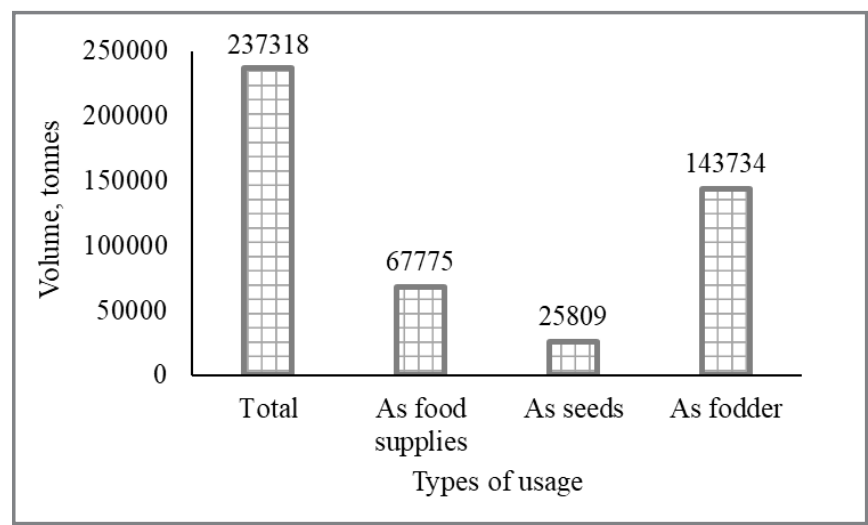

Figure 1 Total volume of available oats by types of usage on 1 December 2017 in tonnes Source: The Committee on Statistics, Ministry of National Economy of the Republic of Kazakhstan, 2018

The figure above illustrates that 143,734 tonnes of oats were available as fodder on 1 December 2017.

The figure below shows how much area was used to harvest oats in Kazakhstan in 2016. 


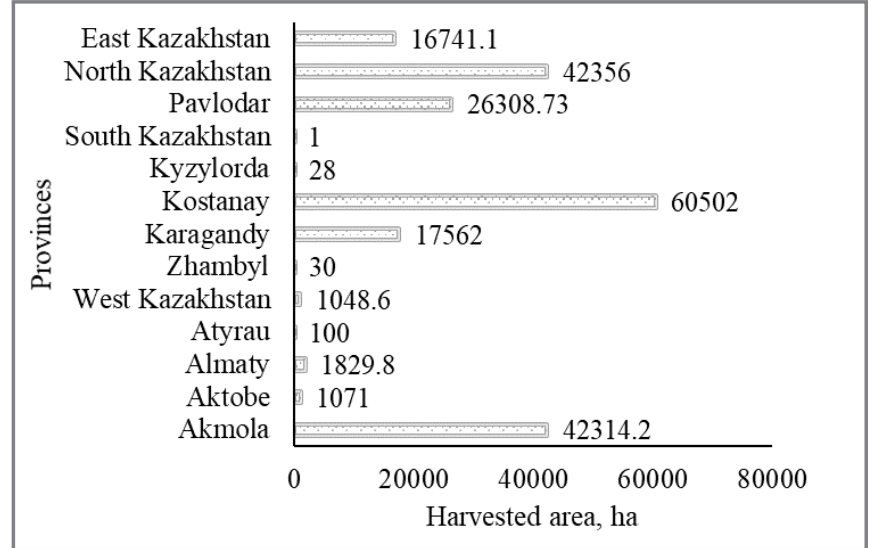

Figure 2 Total harvested area of oats in different provinces of Kazakhstan in 2016 in ha

Source: The Committee on Statistics, Ministry of National Economy of the Republic of Kazakhstan, 2018

The figure above illustrates that the most harvested area for oats in 2016 was in the Kostanay province $-60,502$ ha.

The summary report for the figure above is shown by the figure below.

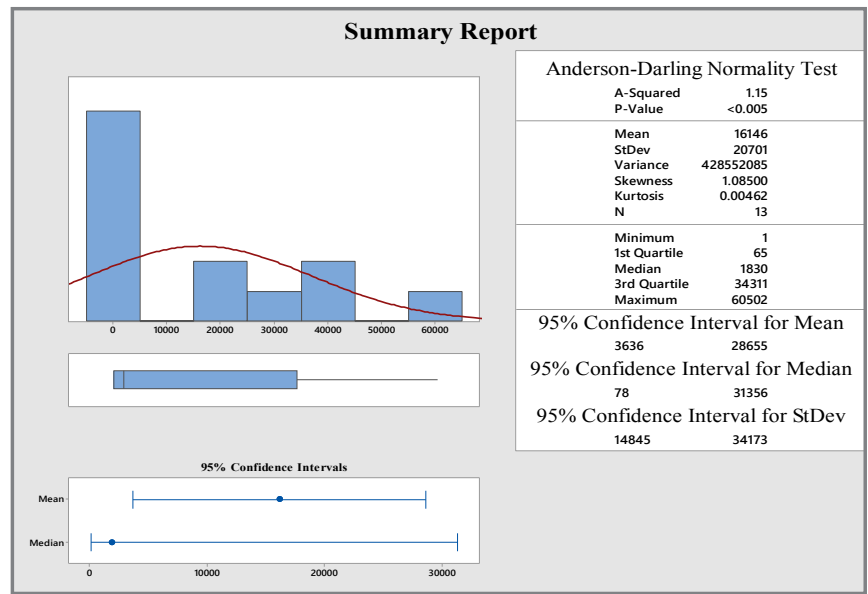

Figure 3 The summary report for harvested area of oats in 2016 Source: The Committee on Statistics, Ministry of National Economy of the Republic of Kazakhstan, 2018

The figure above illustrates that the value of skewness equals to 1.085 . The figure below shows gross collection of oats in Kazakhstan.

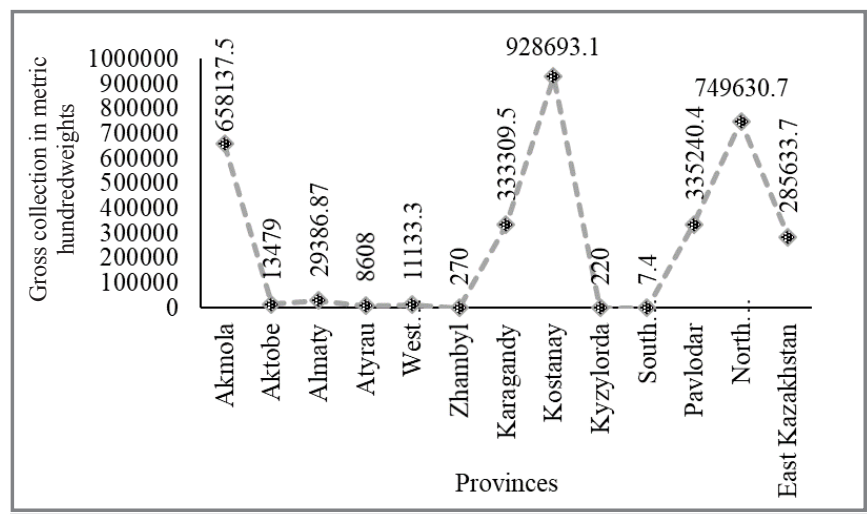

Figure 4 The total gross collection of oats among different provinces of the Republic of Kazakhstan in 2016 in metric hundredweights Source: The Committee on Statistics, Ministry of National Economy of the Republic of Kazakhstan, 2018
The figure above illustrates that the Kostanay province has the highest gross rate -928693.1 metric hundredweights.

The summary report for the figure above is shown by the figure below.

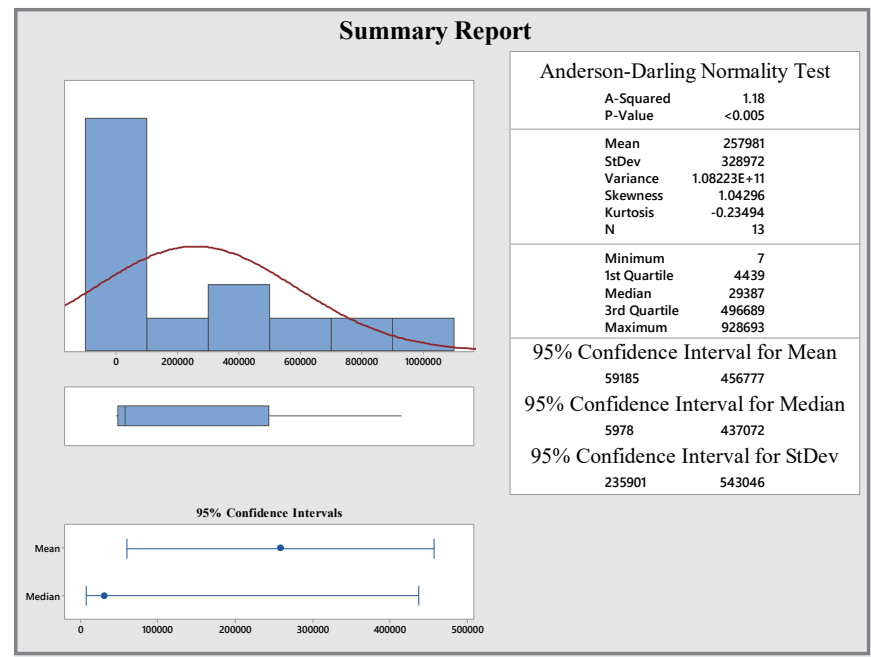

Figure 5 The summary report for gross collection of oats in 2016 Source: The Committee on Statistics, Ministry of National Economy of the Republic of Kazakhstan, 2018

The figure above illustrates that the value of skewness becomes equal to 1.04296 .

The figure below shows the fitted line plot of how much land was used to harvest oats versus the volume of oats collected.

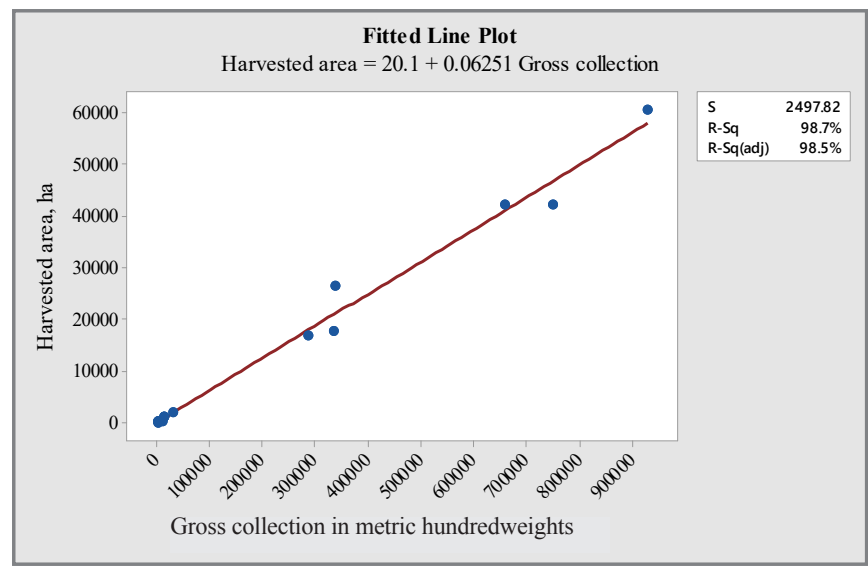

Figure 6 The fitted line plot between the total volumes of land used to harvest oats versus gross collection of the same plant Source: The Committee on Statistics, Ministry of National Economy of the Republic of Kazakhstan, 2018 
The figure above illustrates that the linear regression model formula is "Harvested area $=20.1+0.06251$ Gross collection".

The marginal plot for the same indicators as in the figure above is shown by the figure below.

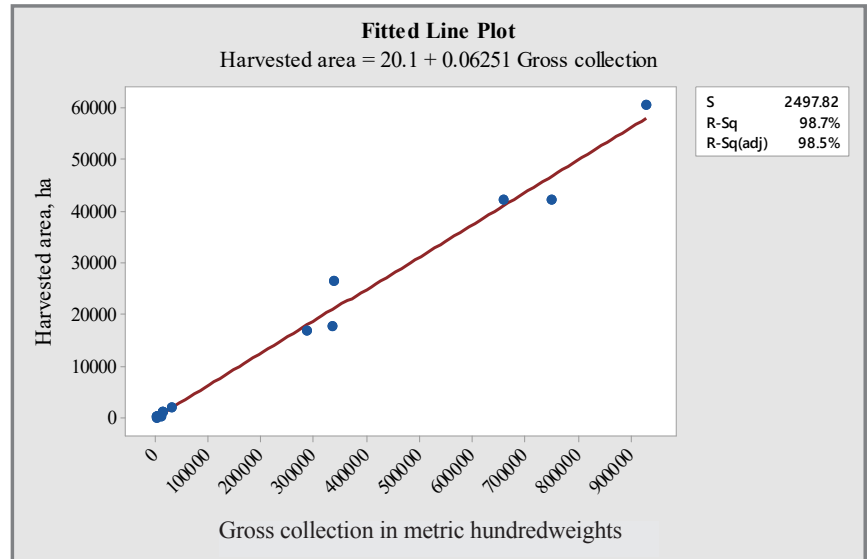

Figure 7 The marginal plot of harvested area versus gross collection of oats in 2016

Source: The Committee on Statistics, Ministry of National Economy of the Republic of Kazakhstan, 2018

The figure above illustrates that at $95 \%$ confidence interval there is a direct link between the area of land used to harvest oats and the volume of oats collected.

The figure below shows the yielding capacity of oats in 2016.

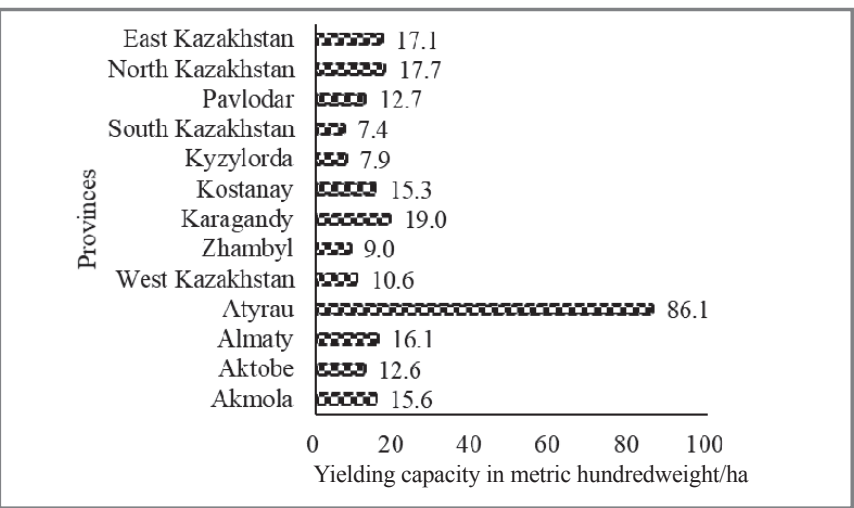

Figure 8 The overall yielding capacity in 2016 for oats in the Republic of Kazakhstan in metric hundredweight/ha

Source: The Committee on Statistics, Ministry of National Economy of the Republic of Kazakhstan, 2018

The figure above shows that the Atyrau province has the highest yielding capacity of oats -86.1 metric hundredweights on average from one hectare.

The summary report for the figure above is shown by the figure below.

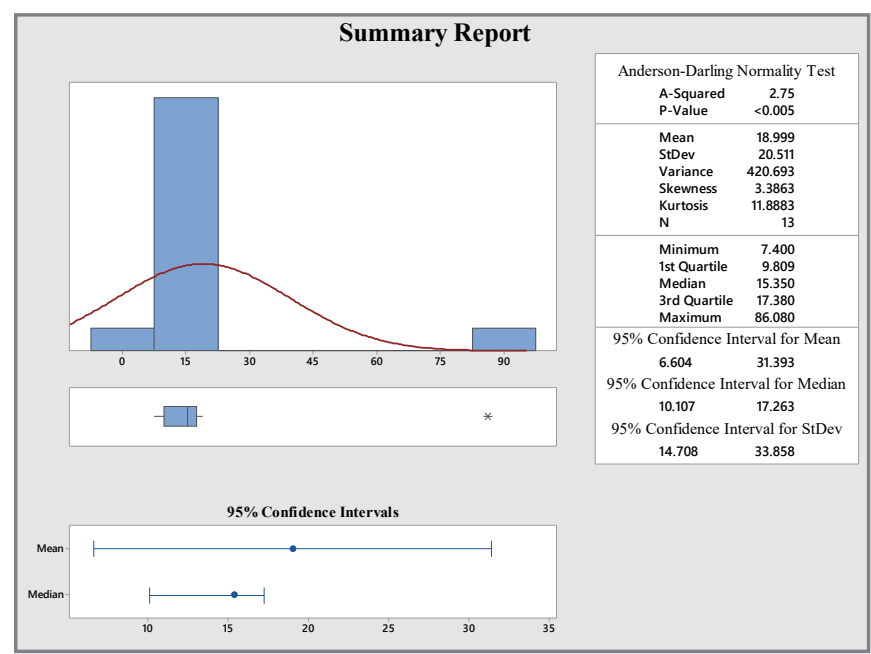

Figure 9 The summary report for the volume of oat's yielding capacity in metric hundredweight/ha

Source: The Committee on Statistics, Ministry of National Economy of the Republic of Kazakhstan, 2018

The figure above illustrates that the value of kurtosis becomes equal to 11.8883 .

The figure below shows the area of agricultural land dedicated to harvesting proso in 2016.

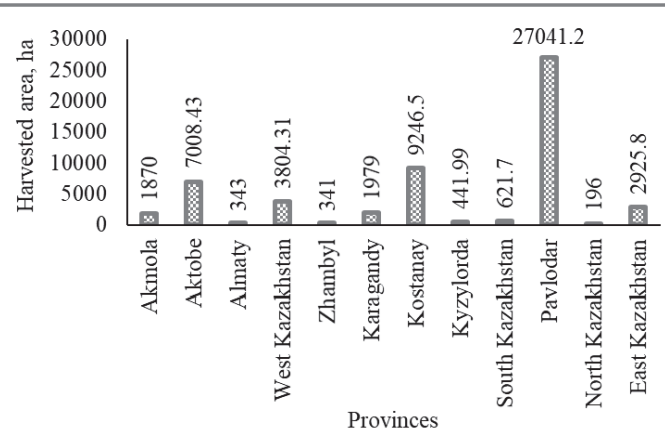

Figure 10 Total harvested area of proso by provinces of Kazakhstan in 2016 in ha

Source: The Committee on Statistics, Ministry of National Economy of the Republic of Kazakhstan, 2018

The figure above illustrates that the Pavlodar province has the highest indicator - 27,041.2 ha.

The summary report for the figure above is shown by the figure below. 


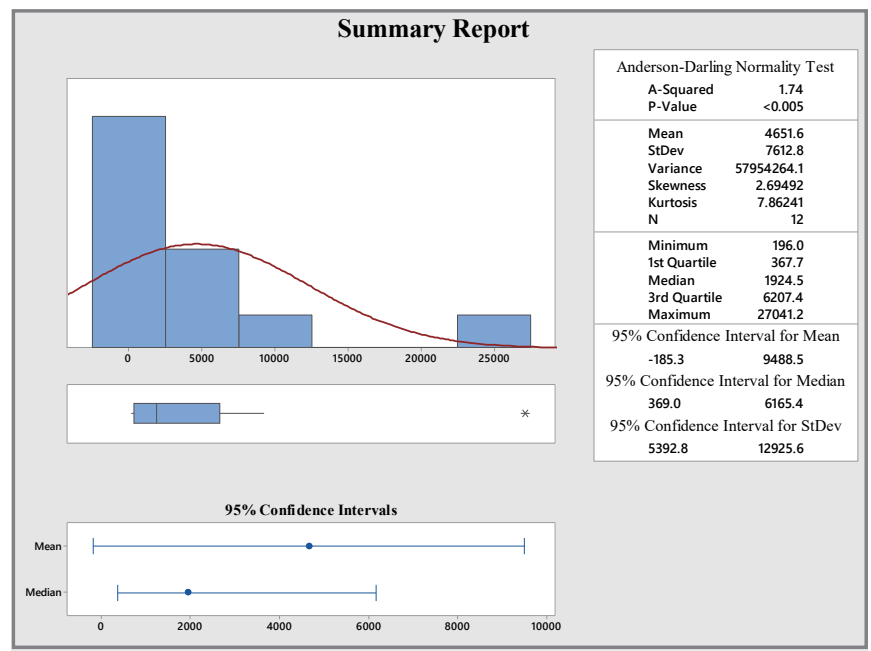

Figure 11 The summary report for harvested area of proso in 2016 Source: The Committee on Statistics, Ministry of National Economy of the Republic of Kazakhstan, 2018

The figure illustrates that the value of standard deviation is 7,612.8.

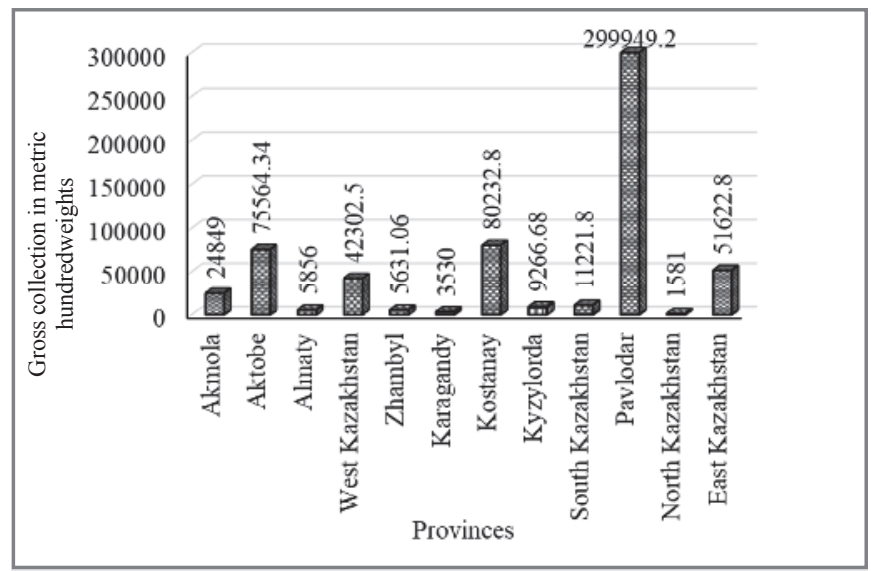

Figure 12 The gross collection of proso in 2016 among different provinces of the Republic of Kazakhstan in metric hundredweights Source: The Committee on Statistics, Ministry of National Economy of the Republic of Kazakhstan, 2018

The figure above illustrates that the biggest volume of proso was collected in Pavlodar province - 299,949.2 metric hundredweights.

The summary report for the figure above is shown by the figure below.

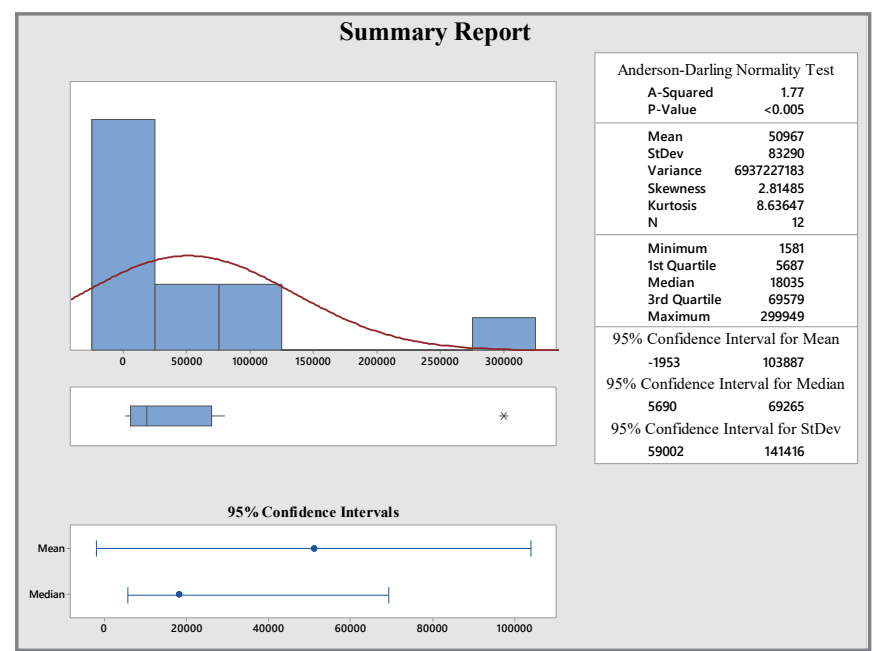

Figure 13 The summary report for the volume of proso collected in 2016 Source: The Committee on Statistics, Ministry of National Economy of the Republic of Kazakhstan, 2018

The figure above illustrates that the value of the standard deviation is 83,290 .

The fitted line plot of proso's harvested area versus its gross collection is shown by the figure below.

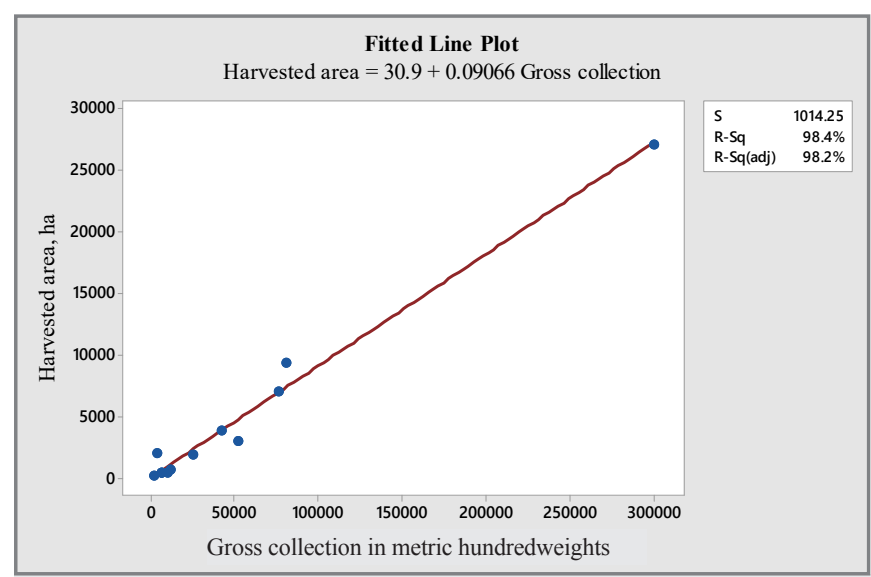

Figure 14 The fitted line plot of proso's harvested area versus proso's gross collection

Source: The Committee on Statistics, Ministry of National Economy of the Republic of Kazakhstan, 2018 
The figure above illustrates that the linear regression model formula is "Harvested area $=30.9+0.09066$ Gross collection".

In the figure below the marginal plot for the same indicators is shown by the figure above.

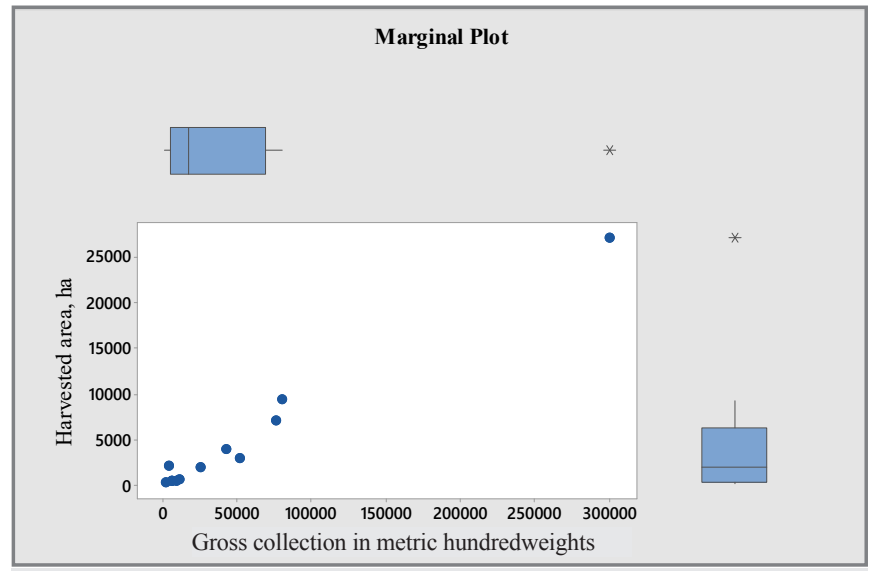

Figure 15 The marginal plot of harvested area of proso versus its gross collection

Source: The Committee on Statistics, Ministry of National Economy of the Republic of Kazakhstan, 2018

The figure above illustrates that at $5 \%$ significance level we cannot reject the presence of the link. in 2016.

The figure below shows how much yielding capacity there was for proso

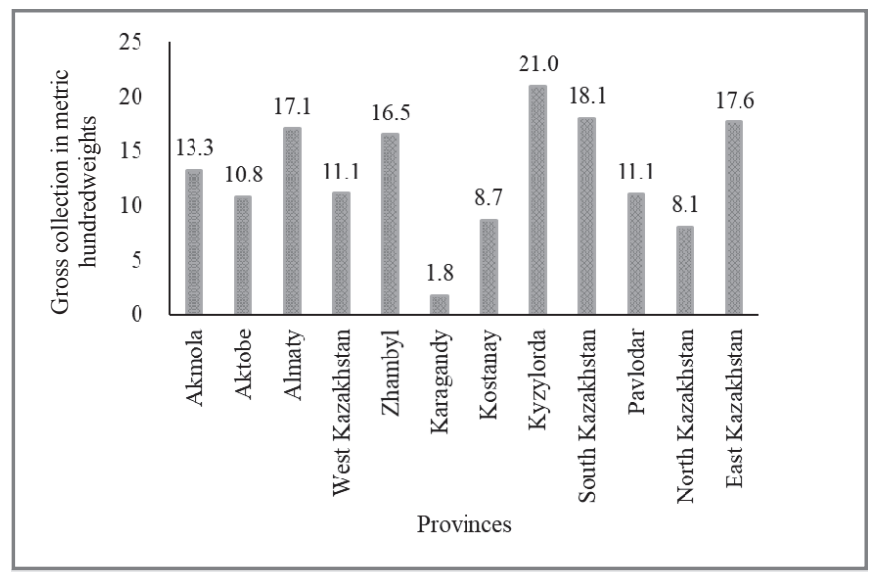

Figure 16 The overall yielding capacity of proso in 2016 for the Republic of Kazakhstan in metric hundredweight/ha

Source: The Committee on Statistics, Ministry of National Economy of the Republic of Kazakhstan, 2018

The figure above illustrates that the highest indicator belongs to the Kyzylorda province: 21 metric hundredweights per each hectare on average.

The summary report for the figure above is shown by the figure below.

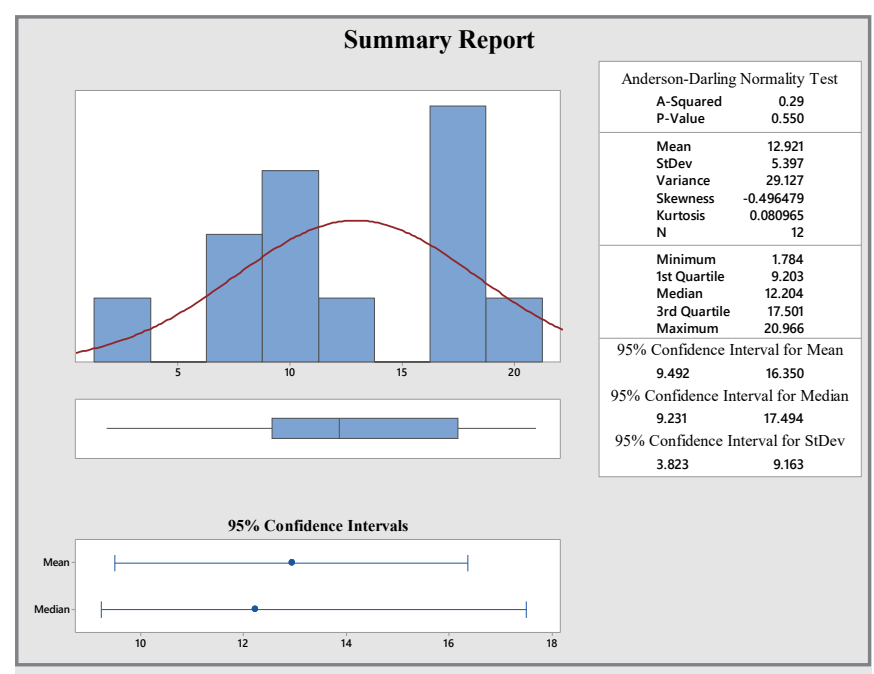

Figure 17 The summary report for the yielding capacity of proso in 2016 Source: The Committee on Statistics, Ministry of National Economy of the Republic of Kazakhstan, 2018

The figure above illustrates that the value of skewness equals to -0.496479 .

The figure below illustrates the Porter's five forces analysis for the oat and proso market.

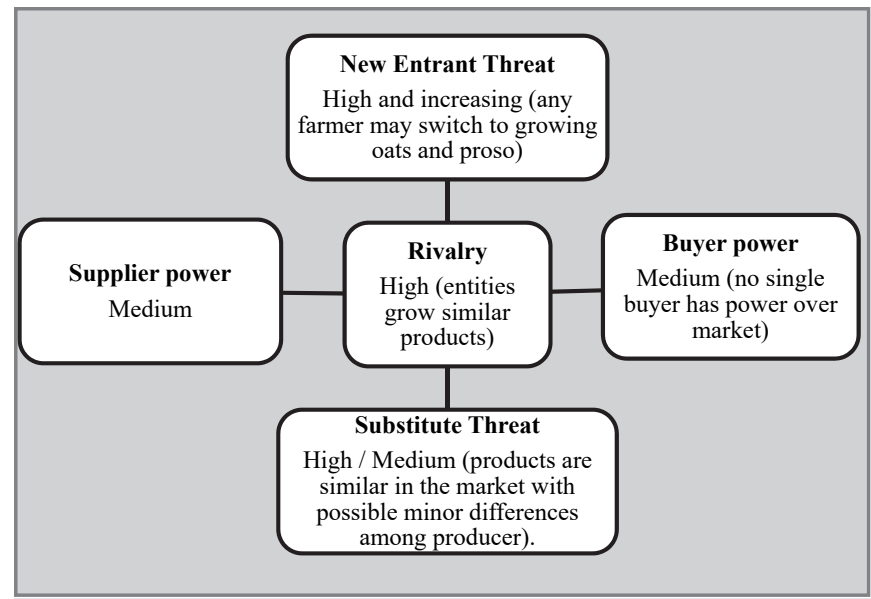

Figure 18 Porter's five forces analysis of the current state in the oat and proso market

Source: Porter, 2008

The figure above shows that there is a very high entrant threat because there are no major barriers for agricultural entities to switch from growing one type of vegetables to oats and proso.

The figure above illustrates that the presence of unethical practices in the agrarian sector is expected to create enormous pressure on the agriculture worldwide.

Due to the continuing prevalence of consumer demand for food oats and proso, both on the domestic and foreign markets, there are also negative trends. Thus, in the structure of oats and proso production, the share of wheat increases, whereas the proportion of feed oats and proso decreases. The share of the main representative of feed oats and proso in 2016 amounted to only $9.6 \%$, although in 2011 it occupied $29.8 \%$. At the same time, over the years there has been a tendency to increase its share in the total volume of oats and proso, as well as the deterioration of the structure according to the main technological indicator - the content of gluten. The main problem of 
The table below is the PESTLE analysis of the oat and proso market.

Table 1 PESTLE analysis of the oat and proso market

\begin{tabular}{|l|l|}
\hline Aspect & \multicolumn{1}{c|}{ Trend } \\
\hline Political & Competition in the oat and proso market increased after Kazakhstan had become a member of the Eurasian Economic Union. \\
\hline Economic & The free-floating exchange rate of tenge may allow Kazakhstani exporters of proso and oat smoother adaptation to the global market. \\
\hline Social & The population of Kazakhstan is expected to grow which may potentially create more workforce available in the agrarian sector. \\
\hline Technologic & Development in biotechnology and other sectors of science may help to create more efficient seeds and oat or proso growing techniques. \\
\hline Competitors & The globalisation and improvements in the global logistics can make it easier for new entrants from further distance to gain access to the internal \\
\hline agricultural market of Kazakhstan.
\end{tabular}

Source: Nazarbayev, 2017

improving the quality remains insufficiently effective use of the bioclimatic potential of the northern regions of the republic for the production of high quality oats and proso of wheat due to the low crop culture, non-compliance with agricultural technology, the lack of purposeful work on the formation of commodity lots and mass depersonalization of lots of high quality oats and proso (Nazarbayev, 2017).

\section{Conclusion}

In Kazakhstan, the project - "Enhancing the transparency of oats and proso of the market in Kazakhstan" - is a joint technical assistance project of the Food and Agriculture Organization of the United Nations (FAO) and the European Bank for Reconstruction and Development (EBRD), implemented in cooperation with national partners. With the assistance of the project, the mechanism for collecting and disseminating information on the oats and proso of the country's market, including a survey of the yield of oats and proso crops, detailed official statistics on the flows of oats and proso and stocks, and a new system of electronic oats and proso receipts has been significantly improved. Also, attracting investments in the storage and transportation of oats and proso are two other priority areas for development. According to FAO: Kazakhstan has a significant potential for storing and transporting oats and proso by rail in years with medium production levels, while the distribution of storage capacities, as well as the availability of equipment for drying oats and proso still require further improvement. Oat and proso processing structure: $79.5 \%$ fall on oatmeal, $9 \%$ for mixed fodder, $3.5 \%$ for alcohol production, $2.9 \%$ for cereals - according to the Union of oats and millet processors in 2011. The production of oatmeal porridge amounted to 4.9 million tonnes, while exports exceeded 3.5 million tonnes. The main producers are the SouthKazakhstan oblast (13\% of the total republican volume), North Kazakhstan (12\%), Akmola and Almaty (9\% each), Karaganda and Kostanay (11\% each), Almaty and Astana. The demand of consumers is increased for products made from oatmeal porridge of coarse grinding, enriched and vitaminized ones. Specialists of the Kazakh Academy of Nutrition note that the diet of the population is dominated by refined food - oatmeal porridge and other high-calorie foods, extremely depleted of vitamins and minerals. Therefore, starting from 2004, 8 enterprises of the republic, including Kostanay oats and proso combined and began to produce oatmeal with vitamin-mineral supplements. The equipment was purchased thanks to a grant from the Asian
Development Bank. The cost of the fortification of 1 ton oats and proso is 1.16 US dollars, i.e. less than $1 \%$ of the cost of oats and proso. According to scientists, for 10 years, the total costs will amount to $\$ 14.5$ million, while the economic benefit will amount to $\$ 89$ million.

In accordance with the recommendations of scientists in the country, a program for fortification has been adopted, the norms for introducing an iron-vitamin premix for oatmeal porridge of the highest and first grade have been determined. According to the information of the Union of oats and millet of processors of the Republic of Kazakhstan, 17 oats and proso enterprises (including "Agrocenter Astana", "Altyn-Diirmen", "Tsesna-Astyk") have mastered the premix enrichment technology. The premix is imported from the USA. There is a positive tendency to increase the production of cereals. This is caused by the reaction of the domestic commodity producer to the growing consumer demand of the national market and the development of the import substitution process. Hence the conclusion that in order to expand the export of oats and proso processing products, it is necessary to develop the material and technical base of the groats industry, and also to eliminate the organizational disconnection of the procurers and processors in order to create the most efficient single technological cycle, including all stages growing, harvesting, storage and processing. The diversification of industries, in particular, an increase in the range and output of products from oats and millet, also requires its solution. For the development of production of readyto-eat breakfast cereals, confectionery products from oatmeal, an increase in the assortment, improvement of taste qualities and registration for the purpose of import substitution and their supply for export are necessary.

\section{References}

BECKETT, S. 2015. Physico-Chemical Aspects of Food Processing. Glasgow : Blackie Academic and Professional, 2015.

COHEN, B. 2015. Currency Power: Understanding Monetary Rivalry. Princeton and Oxford: Princeton University Press, 2015.

FERGUS, M. - JANDOSOVA, J. 2013. Kazakhstan: Coming of Age. London : Stacey International, 2013.

INDEX MUNDI. 2017. Kazakhstan 0ats Production by Year. Available: https://www. indexmundi.com/agriculture/?country $=k z \&$ commodity $=0$ ats \&graph $=$ production [Accessed: 9 January 2018].

KRISHNA, K. 2013. Agroecosystems: Soils, Climate, Crops, Nutrient Dynamics and Productivity. Toronto : Apple Academic Press, 2013. 
KUO, C. - MAVLYANOVA, R. - KALB, T. 2016. Increasing Market-Oriented Vegetable Production: in Central Asian and the Caucasus through Collaborative Research and Development. Tainan, Taiwan : AVRDC-WorldVegetableCenter, 2016.

MIDDLE EAST AND CENTRAL ASIA DEPARTMENT, International Monetary Fund. 2015. Republic of Kazakhstan: 2015 Article IV Consultation-Press Release; Staff Report for the Republic of Kazakhstan. Washington, D.C. : International Monetary Fund, 2015.

NAZARBAYEV, N. 2017. The President of Kazakhstan Nursultan Nazarbayev's Address to the Nation of Kazakhstan. January 31, 2017. Available: http://www.akorda.kz/ en/addresses/addresses_of_president/the-president-of-kazakhstan-nursultannazarbayevs-address-to-the-nation-of-kazakhstan-january-31-2017 [Accessed: 9 January 2018].

NAZARBAYEV, N. 2015. The 100 concrete steps set out by President Nursultan Nazarbayev to implement the five institutional reforms. May 20, 2015. Available: https:// strategy2050.kz/en/page/message_text2014 [Accessed: 9 January 2018].

OECD. 2013. OECD Review of Agricultural Policies OECD Review of Agricultural Policies: Kazakhstan 2013. Paris : OECD Publishing, 2013.

PETERSEN, K. 2011. Corporate Risk and National Security Redefined. Abingdon, Oxon : Routledge, 2011.

PORTER, M. 2018. Competitive Strategy: Techniques for Analyzing Industries and Competitors. New York : The Free Press, 2018.
THE COMMITTEE ON STATISTICS, Ministry of National Economy of the Republic of Kazakhstan. 2018. Presence grain and bean cultures on 1 December 2017. Available: http://stat.gov.kz/getlmg?id=ESTAT243919 [Accessed: 9 January 2018].

THE COMMITTEE ON STATISTICS, Ministry of National Economy of the Republic of Kazakhstan. 2018. Valovyi sbor 2016. Available: http://stat.gov.kz/ getlmg?id=ESTAT205410 [Accessed: 9 January 2018].

THE NATIONAL BANK OF KAZAKHSTAN. 2017. Official exchange rates, 2017. Available: http://www.nationalbank.kz/cont/2017\%20eng8.pdf [Accessed: 12 0ctober 2017].

UPADHYAYA, H. - SINGH, S. 2016. Genetic and Genomic Resources for Grain Cereals Improvement. London : Academic Press, 2016.

WEBSTER, F. - WOOD, P. 2016. Oats: Chemistry and Technology. St. Paul, Minnesota, USA : AACC International Inc, 2016.

\section{Contact address}

Marita Baltabayevna Kadyrbekova

Kazakh National Agrarian University

Almaty, Republic of Kazakhstan

e-mail:marita_kadyrbekova@mail.ru 